\title{
PERLINDUNGAN KONSUMEN TERHADAP PENIPUAN YANG DILAKUKAN BROKER FOREX ILEGAL
}

\author{
I Made Aswin Ksamawantara, Johannes Ibrahim Kosasih, I Made Minggu Widyantara \\ Fakultas Hukum, Universitas Warmadewa, Denpasar-Bali, Indonesia \\ aswksamawantara@gmail.com, johannesibrahim26@gmail.com, mademinggu21@gmail.com
}

\begin{abstract}
Abstrak
Fenomena Foreign Exchange (Forex) yang berjalan pada bidang investasi dan dapat membantu pembangunan lndonesia. Saat ini forex menjadi trend yang mewabah dan menarik perhatian banyak pihak, baik investor atau publik pada umumnya. Valuta asing atau forex merupakan suatu jenis perdagangan atau transaksi yang rnemperdagangkan mata uang suatu negara terhadap mata uang negara lainnya yang melibatkan pasar-pasar uang utama di dunia selama 24 jam secara berkesinambungan, maka dalam hal ini dibutuhkan sebuah perlindungan hukum. Tujuan penelitian ini yaitu untuk menganalisa perlindungan hukum dalam transaksi Forex serta sanksi Hukum yang diberikan oleh Pemerintah terhadap Kegiatan Broker Forex Ilegal. Penelitian ini menggunakan rnetode normatif yang menggunakan pendekatan perundang-undangan (statute approach). Sumber data yang digunakan adalah sumber data primer dan sumber data sekunder. Setelah data hukum primer dan data hukum sekunder terkumpul selanjutnya data tersebut akan diolah dan dianalisis dengan menggunakan metode pengolahan data hukum secara sistematis. Hasil penelitian menunjukkan bahwa kasus dugaan penipuan investasi bodong berkedok trading forex rnelibatkan pialang ilegal dari Guardian Capital Group (GCG) Asia, yang merugikan konsumen. Sejalan dengan itu pemerintah mengeluarkan aturan hukum yaitu Undang-Undang No.8 Tahun 1999 tentang Perlindungan Konsumen. Hukum Perlindungan Konsumen yang telah ditetapkan oleh pemerintah menjadi dasar hukum yang akurat dan penuh optimisme dalam melindungi hak-hak konsurnen.
\end{abstract}

Kata Kunci: Investasi, Penipuan, Perlindungan Konsumen

\begin{abstract}
The phenomenon of Foreign Exchange (Forex) that runs in the investment sector and can help the development of Indonesia. Currently forex is a trend that is endemic and attracts the attention of many parties, both investors and the public in general. Foreign exchange or forex is a type of trade or transaction that trades the currency of a country against the currencies of other countries involving the main money markets in the world for 24 hours continuously, so in this case a legal protection is needed. The purpose of this research is to analyze legal protection in Forex transactions and legal sanctions imposed by the government on illegal Forex broker activities. This research uses a normative method that with a statutory approach. Sources of data used are primary data sources and secondary data sources. After primary legal data and secondary legal data are collected, the data will then be processed and analyzed using systematic legal data processing methods. The results showed that the alleged fraudulent investment fraud case under the guise of forex trading involved illegal brokers from the Guardian Capital Group (GCG) Asia, which harmed consumers. In line with that, the government issued a legal rule, namely Law No.8 of 1999 concerning Consumer Protection. The Consumer Protection Law that has been set by the government is the legal basis that is accurate and full of optimism in protecting consumer rights.
\end{abstract}

Keywords: Investment, Fraud, Consumer Protection

\section{PENDAHULUAN}

Salah satu perdagangan jasa yang banyak yang dilakukan saat ini adalah berinvestasi. Investasi merupakan suatu kegiatan bisnis yang dapat memberikan keunrungan (return), tetapi juga memiliki resiko (risk). Semakin tinggi risiko sebuah investasi maka semakin tinggi potensi keuntungannya (Serfianto et al., 2013). Fenomena Foreign Exchange (Forex) yang berjalan pada bidang investasi dan dapat membantu pembangunan Indonesia. Saat ini forex menjadi trend yang mewabah dan menarik perhatian banyak pihak, baik investor atau publik pada umumnya. Valuta asing atau forex merupakan suatu jenis perdagangan atau transaksi yang memperdagangkan mata uang suatu Negara terhadap mata uang negara lainnya yang melibatkan pasar-pasar uang utama di dunia selama 24 jam secara 
berkesinambungan. Perdagangan valas menjadi pasar keuangan terbesar di dunia, dengan volume perdagangan harian melebihi USO 4 triliun sehingga tidak dapat diragukan lagi (Singh, 2014).

Pelaku usaha forex disebut sebagai trader. Trader menjual dan membeli mata uang secara terus menerus, regular dengan jumlah yang relatif kecil dan konsisten untuk mendapatkan keuntungan. Dalam forex pelaku usaha/nasabah dapat melakukan transaksi, baik dari rumah ataupun dari mana saja, apabila terdapat jaringan internet. Keuntungan forexdapat dilihat dari dua arah, baik pada saat harga turun maupun harga naik. Hal itulah yang menjadikan forex trading menjadi trend pilihan investasi saat ini selain pasar modal yang menggiurkan karena likuiditas yang tinggi dan tingkat pengembalian investasi (return on investment) juga tinggi (Kosasih \& Haykal, 2020). Kasus dugaan penipuan investasi bodong berkedok trading forex melibatkan pialang ilegal dari Guardian Capital Group (GCG) Asia. Total jumlah korban pada kasus ini mencapai hingga 34.000 orang dengan total kerugian sebesar Rp. 1,8 triliun. Dalam perkara ini, puluhan korban telah melaporkan beberapa agen ke pihak kepolisian, antara lain Dittipideksus Bareskrim Mabes Polri, Polda Metro Jaya, serta Polda Jatim. Tak hanya itu, para korban ada juga yang melaporkan ke Polrestabes Surabaya dan Polresta Malang. Salah satu perwakilan korban penipuan berbasis Multilevel Marketing (MLM) mengatakan, ia melaporkan leademya, Robby, karena merasa dirugikan sebesar Rp. 300 juta.

Penanggungjawab atas kasus ini ada diatasnya (leader) yakni Robby. Korban lainnya mengatakan ia bergabung dengan GCG sejak bulan Mei. Sedangkan kerugian yang dialami, ia mengaku sebesar Rp. 100.000.000,. Para korban berminat terhadap investasi GCG Asia ini karena dijanjikan keuntungan (profit) sebesar 5\% hingga 25\% oleh leader. Hukum Perlindungan Konsumen yang telah ditetapkan oleh pemerintah menjadi dasar hukum yang akurat dan penuh optimisme dalam melindungi hak-hak konsumen. Hukum Perlindungan Konsumen meru pakan cabang dari Hukum Ekonomi. Alasannya, permasalahan yang diatur dalam hukum konsumen berkaitan erat dengan pemenuhan kebutuhan barang dan/atau jasa. Dengan diundang-undangkannya masalah perlindungan konsumen, dimungkinkan dilakukannya pembuktian terbalik jika terjadi sengketa antara konsumen dan pelaku usaha. Konsumen yang merasa haknya dilanggar bisa mengadukan dan memproses perkaranya secara hukum di Badan Penyelesaian Sengketa Konsumen (BPSK). Selain itu, pemerintah mengeluarkan aturan hukum berupa Undang-Undang No.32 Tahun 1997 mengenai Perdagangan Berjangka Komoditi yang sudah diamandemenkan menjadi Undang-Undang No. 10 Tahun 2011. Dengan adanya aturan hukum Undang-Undang diatas maka kedepannya masyarakat dapat terlindungi dari praktik-praktik perdagangan yang merugikan.

Dalam praktiknya, banyak ditemukan nasabah yang mengalami kerugian dalam Forex karena pialang berjangka melakukan pelanggaran terhadap peraturan perundang-undangan ataupun pialang berjangka cidera janji (wanprestasi) (Wardhani, 2016). Jika pialang berjangka melakukan pelanggaran maka dikenakan sanksi pidana penjara paling singkat 5 (lima) tahun dan paling lama 10 (sepuluh) tahun dan denda paling sedikit Rp. 10.000.000.000,- (sepuluh miliar rupiah) dan paling banyak Rp. 20.000.000.000,- (dua puluh miliar rupiah) sebagaimana diatur dalam Pasal 71 ayat (1) UndangUndang Perdagangan Berjangka Komoditi (Purnomo et al., 2013). Namun hal ini dapat diminimalisir dikarenakan BAPPEBTI (Pengawas dalam perdagangan berjangka) yang mempunyai jabatan dibawah Menteri Perdagangan namun dibentuk oleh undang-undang yang memiliki wewenang membuat peraturan; menerbitkan izin usaha bagi bursa, lembaga kliring, serta pialang; mengawasi bursa dan lembaga kliring; melakukan pemeriksaan, penyidikan serta tindakan dan sanksi yang diperlukan untuk perlindungan masyarakat (Renti, 2012).

Berdasarkan uraian diatas, dirumuskannya tujuan penelitian ini yaitu menganalisa perlindungan hukum dalam transaksi Forex serta sanksi hukum yang diberikan oleh Pemerintah terhadap Kegiatan Broker Forex Ilegal.

\section{METODE PENELITIAN}

Tipe penelitian ini menggunakan penelitian kepustakaan yang bersifat yuridis normatif kualitatif yang sumbernya diperoleh dari bahan pustaka dan studi dokumen. Sehingga peneliti dengan penelitian hukum yuridis normatif kualitatif ini bermaksud agar ditemukannya solusi dari masalah dengan menggunakan bahan-bahan kepustakaan, teori-teori hukum yang ada termasuk Peraturan PerundangUndangan. Sehingga dapat dikaji permasalahan dari penelitian ini untuk selanjutnya dapat ditarik kesimpulan atas apa yang diperoleh. Sumber data yang digunakan adalah sumber data primer dan sumber data sekunder. Sumber data primer yaitu penelitian yang diperoleh dari sumber Kitab 
Undang-Undang Hukum Perdata, Kitab Undang-Undang Hukum Pidana, UU No. 8 Tahun 1999, UU No. 32 Tahun 1997. Sumber data sekunder dalam penelitian ini adalah buku referensi, jurnal hukum, dan yang lain terkait dengan permasalahan. Setelah data hukum primer dan data hukum sekunder terkumpul selanjutnya data tersebut akan diolah dan dianalisis dengan menggunakan metode pengolahan data hukum secara sistematis.

\section{HASIL DAN PEMBAHASAN}

\section{Perlindungan Hukum Dalam Transaksi Forex}

Tujuan dasar negara hukum adalah memberikan perlindungan hukum bagi rakyatnya. Perl indungan hukum ini sangat penting karena menyangkut banyak pihak (kepentingan pemodal dan masyarakat) maka dari itu diperlukan adanya pengawasan dari Otoritas Publik, yaitu BAPEPAM. Lembaga inilah yang menjadi benteng terdepan dalam penegakan prinsip-prinsip UU Pasar Modal. Sementara itu, implementasi kewenangan Bapepam sebagai lembaga pengawas dapat dilakukan secara mandiri (Fuadi, 2001):

a. Preventif, yaitu berupa aturan, pedoman, pembinaan dan pengawasan;

b. Represif, yaitu berupa pemeriksaan, penyidikan sanksi.

Undang-Undang Perdagangan Berjangka Komoditi telah mengkonfirmasi BAPPEBTI adalah lembaga yang bertanggung jawab mengawasi dan mengembangkan aktivitas perdagangan berjangka setiap hari dalam aktivitas perdagangan berjangka. Pengaturan yang relevan artinya, pengaturan teknis yang dilakukan BAPPEBTI dalam membuat peraturan pelaksanaan teknis sebagai penjabaran lebih lanjut dari Undang-Undang, Peraturan Pemerintah, Peraturan Presiden, dan Peraturan Menteri. Selain itu, BAPPEBTI juga memberikan arahan berdasarkan perkembangan aktivitas pasar agar aktivitas perdagangan komoditas berdasarkan kontrak berjangka, kontrak derivatif syariah dan I atau kontrak derivatif lainnya di SPA dapat dilakukan secara teratur, wajar, efektif, dan transparan. Untuk menjamin bahwa semua kegiatan dilaksanakan sesuai dengan peraturan perundang-undangan yang berlaku, diperlukan pengawasan tentang kegiatan Bursa Berjangka dilakukan di lokasi dan melaporkan kepada BAPPEBTI. BAPPEBTI sebagai institusi yang memberi perlindungan kepada investor dalamforex trading agar tidak terjadi kerugian, antara lain membujuk dengan menjanjikan keuntungan, memberikan informasi yang menyesatkan, tidak menyalurkan amanat nasabah sesuai dengan perintah, melaksanakan transaksi tanpa sepengetahuan atau tanpa perintah nasabah, tidak menjelaskan resiko yang dihadapi calon nasabah, dan tidak menempatkan dana nasabah pad a rekening yang terpisah. Penegakan hukum dalam bentuk perlindungan hukum dalam kegiatan ekonomi bisnis khususnya pasar modal tidak bisa dilepaskan dari aspek hukum perusahaan (Hadikusuma \& Sumantoro, 1996) khususnya perseroan terbatas, karena perlindungan hukum dalam pasar modal rnelibatkan para pihak pelaku pasar modal terutama pihak emiten, investor dan Lembagalembaga penunjang kegiatan pasar modal yang mana para pihak tersebut didominasi oleh subjek hukum berupa badan hukum berbentuk perseroan terbatas. Perlindungan secara umum yang diberikan BAPPEBTI, nasabah yang mengalami kerugian juga mendapatkan perlindungan secara khusus yang diatur dalam BAB VI Undang-Undang Perdagangan Berjangka Komoditi mengenai dana kompensasi. Menurut Pasal 46 ayat (1), dana kompensasi merupakan dana yang digunakan oleh Bursa Berjangka untuk membayar ganti rugi kepada nasabah yang bukan anggota Bursa Berjangka yang timbul akibat cidera janji (wanprestasi) atau kesalahan dari Pialang Berjangka.

Penipuan menurut Pasal 1328 KUHPerdata dengan tegas menyatakan, penipuan merupakan suatu alasan unruk pembatalan perjanjian, apabila tipu muslihat, yang dipakai oleh suaru pihak, adalah sedemikian rupa hingga terang dan nyata bahwa pihak yang lain tidak telah membuat perikatan itu jika tidak dilakukan tipu muslihat tersebut. Penipuan tidak harus dipersangkakan melainkan harus dibuktikan. Dalam hal penipuan, pihak yang ditipu, memberikan pemyataan yang sesuai kehendaknya, tetapi kehendaknya itu , karena adanya daya tipu yang sengaja diarahkan ke suatu yang bertentangan dengan kehendak yang sebenarnya, yang seandainya tidak ada penipuan, merupakan tindakan yang benar. Jadi penipuan tidak hanya pernyataan yang bohong atau palsu, melainkan harus ada serangkaian kebohongan (samenweefsel van verdichsteleny, serangkaian cerita yang tidak benar, dan setiap tindakan/sikap yang bersifat menipu (Satrio, 1993). Berikut beberapa contoh kasus Broker Forex llegal yang terjadi di masyarakat:

1) MFX Broker tengah dilanda prahara sejak pertengahan tahun 2016 dan belumjuga selesai hingga tahun 2017, hal ini diduga kuat scam. Banyak trader forex yang sebelumnya menjadi 
nasabah MFX menyatakan permintaan withdrawal mereka ditolak atau pending hingga berbulan-bulan. MFX telah berdiri sejak tahun 2006, dengan kantor pusat di Rusia, tetapi juga memiliki kantor dan regulasi dari Belize. Pialang ini sempat menjadi saJah satu favorit trader Indonesia dengan banyaknya IB tersebut di berbagai wilayah. Namun, pada Agustus 2016 salah saru IB terdepannya. MFX Broker Jakarta, merilis sebuah peringatan di forum kaskus. Dal am peringatan tersebut, pengelola mfxbrokerindonesia.com menyatakan telah mernutus hubungan dengan MFX Pusat, karena proses withdrawal yang sangat sulit bahkan penarikan dana senilai ribuan hingga puluhan ribu dolar tidak dibayarkan. Situs LB terse but kini tel ah offline, tetapi bagian blognya dipenuhi oleh tuntutan withdrawal yang belum juga dibayarkan

2) 23 Karyawan Bank Tertipu Trading Forex Rp 17 M. Panji Permana seorang pria sudah 17 tahun rnenjadi seorang piaJang dan ikut program trading Forex. Diantaranya yairu, Insta Forex, XM, dan Okta FX. Dengan keahliannya sebagai piaJang, panji mencari investor agar mendapatkan keuntungan yang besar. Panji sendiri menjanjikan keuntungan sebesar 5 persen setiap bulan kepada investornya untuk uang yang dikelola melalui trading Forex.

Perlindungan hukum secara preventif dalam Undang-Undang No. 32 Tahun 1997 belum mengakomodir sebagaimana terdapat dalam ketentuan dari Pasal 52 ayat (1). Pasal 52 ayat (1) hanya berkaitan dengan perdagangan mengenai Pialang Berjangka. Mengenai kasus penipuan broker forex ilegal ini, belum ada upaya hukum yang dapat dilakukan oleh nasabah. Belum adanya upaya hukum yang jelas mengatur mengenai Perlindungan Hukum apa saja yang diperoleh nasabah. Seperti pada Undang-Undang No. 10 Tahun 2011 tentang Perdagangan Berjangka Komoditi yang hanya menjelaskan tentang bagaimana bentuk penyelesaian dan sistem pelaporannya. Tetapi proses dari penyelesaian dan pelaporan untuk kasus penipuan tersebut tidak jelas. Perlindungan hukum terhadap nasabah oleh Pialang Berjangka berdasarkan Undang-Undang Nomor 32 Tahun 1997 tentang Perdagangan Berjangka Komoditi yang diatur dalam Pasal 52 ayat (1) serta ketentuan dalam penyelenggaraan terhadap Undang-Undang Nomor 32 Tahun 1997 yaitu Peraturan Pemerintah Republik Indonesia Nomor 9 tahun 1999 tentang Penyelenggara Perdagangan Berjangka Komoditi. Praktik dalam pelaksanaan oleh Perusahaan Pialang Berjangka atau Wakil Pialang tidak terimplementasikan dengan baik. Pasal 52 ayat (1) Undang-undang Nomor 32 tahun 1997 tentang Perdagangan Berjangka Komoditi yang juga diatur dalam Peraturan BAPPEBTI Nomor 64/BAPPEBTI/Per/1/2009 tentang Ketentuan Teknis Perilaku Pialang Berjangka. Pasal 52 ayat (1) yang berbunyi: Pialang Berjangka diiarang melakukan transaksi Kontrak Berjangka untuk rekening investor, kecuali telah menerima perintah tertulis untuk setiap kali transaksi dari investor atau kuasanya yang ditunjuk secara tertulis untuk mewakili kepentingan Investor yang bersangkutan.

\section{Sanksi Hukum yang diberikan oleh Pemerintah terhadap Kegiatan Broker Forex Ilegal}

Forex dalam praktiknya, Banyak nasabah masih ditemukan mengalami kerugian akibat Pialang Berjangka melakukan pelanggaran terhadap peraturan perundang-undangan. Misalnya pialang berjangka yang tidak memiliki izin usaha BAPPEBTI tetapi menjalankan kegiatan usahanya. Ini biasanya dilakukan oleh pialang berjangka asing. Pialang Berjangka dari luar negeri tersebut menjanjikan keuntungan yang besar sehingga nasabah tergiur untuk berinvestasi dalam forex trading. Sering terjadi manipulasi transaksi dalamforex trading yang mengakibatkan para nasabah mengalami kerugian hingga miliaran rupiah. Dalam hal ini, berikut akan dijelaskan beberapa penyimpangan yang biasanya dilakukan oleh pialang berjangka:

1) Pelanggaran persyaratan lisensi Pialang Berjangka

2) Pelanggaran persyaratan lisensi Wakil Pialang Berjangka

3) Pelanggaran terhadap ketentuan tentang Dana Nasabah (Margin)

4) Risiko melanggar ketentuan terkait penyampaian dokumen informasi perusahaan dan dokumen pemberitahuan

5) Pelanggaran larangan perdagangan.

Apabila Pialang Berjangka melakukan pelanggaran, maka akan dikenakan sanksi pidana penjara terlama 8 (delapan) tahun, denda maksimal Rp. 10.000.000.000 (sepuluh Miliar Rupiah). Dapat dilihat bahwa Undang-Undang Perdagangan Berjangka Komoditi mengatur hukuman penjara dan denda bagi para pialang yang melanggar regulasi bidang perdagangan berjangka komoditi. BAPPEBTI pada Undang-Undang Perdagangan Berjangka Komoditi juga mengatur sanksi administratif bagi Pialang yang melanggar ketentuan izin usaha, Pasal 69 mengatur: 
1) BAPPEBTI berhak memberikan sanksi administratif atas pelanggaran ketentuan undangundang ini dan/atau ketenruan pelaksanaan tersebut dilakukan oleh pihak-pihak yang telah memperoleh izin usaha BAPPEBTI, izin yang telah disetujui, dan sertifikat pendaftaran BAPPEBTI.

2) Sanksi administratif pada ayat (1) menyebutkan:

a. Peringatan tertulis;

b. Denda administratif, yaitu kewajiban membayar dalam jumlah tertentu;

c. Pembatasan aktivitas;

d. Pembekuan aktivitas;

e. Cabut lisensi;

f. Cabut lisensi;

g. Persetujuan dibatalkan;

h. Sertifikat pendaftaran dibatalkan.

Selain itu, dengan atau tanpa sanksi tertulis sebelumnya, dapat dikenakan denda administratif, izin usaha dibatasi dan dibekukan, izin usaha dicabut, izin dicabut, sertifikat pendaftaran diserujui dan dibatalkan, dan sanksi administratif dapat dijatuhkan sendiri atau digabungkan dengan sanksi lainnya.

\section{SIMPULAN DAN SARAN}

\section{Simpulan}

Perdagangan Forex memerlukan landasan hukum yang kuat dan jelas yang dikeluarkan pemerintah sebagai alat atau pedoman bagi para nasabah perdagangan Jorex. Pasal 31 Undang-Undang Nomor 32 Tahun 1997 tentang Perdagangan Berjangka Komoditi mengatur tentang pialang berjangka atau Forex. Perizinan Pialang Berjangka dikeluarkan oleh Kepala Bappebti berupa Surat Kepurusan o.07/ Bappebti/ KP/ X 1999. Selain itu adapula Pasal 37 Peraturan Pemerintah Nomor 9 Tahun 1999 Tentang Penyelenggaraan Perdagangan Berjangka Komoditi. Pada praktiknya masih ditemukan Forex ilegal yang tidak mempunyai izin resmi namun dapat beroperasi bebas. Pengawasan perdagangan berjangka komoditi dilakukan langsung oleh BAPPEBTI sesuai dengan Pasal 4 Undang-Undang Nomor 10 Tahun 2011 (Perubahan atas Undang-Undang omor 32 Tahun 1997). Pada Undang-Undang No. 32 Tahun 1997 hanya mengatur penyelesaian perselisihan dan tidak menyebutkan lebih lanjut bentuk perlindungan hukum yang harus diambil Pialang Berjangka atau Forex. Penyelesaian perselisihan antara konsumen dengan Pialang Berjangka dilakukan dengan penyelesaian perdata melalui Pialang Berjangka internal, penyelesaian melalui lembaga bursa berjangka dan penyelesaian melalui BAPPEBTI. Sedangkan, penyelesaian secara pidana dilakukan oleh penyidik pegawai negeri sipil BAPPEBTI, dan dapat dilakukan melalui Lembaga Kepolisian dan Lembaga Peradilan Pidana.

\section{Saran}

Kepada Pemerintah, dalam Pasal I Undang-Undang No.8 tahun 1999 tentang Perlindungan Konsumen (UUPK), menyatakan pengertian mengenai konsumen adalah "setiap orang pemakai barang atau jasa yang tersedia di masyarakat, baik bagi kepentingan diri sendiri, keluarga, orang lain maupun makhluk hidup lain dan tidak untuk diperdagangkan". Berdasarkan Undang-Undang tersebut bahwa sudah jelas tugas pemerintah adalah memberikan perlindungan kepada konsumen, pemerintah wajib melindungi konsumen agar nantinya tidak dirugikan oleh pihak rnanapun. Pemerintah juga seharusnya membuatkan peraturan yang mengikat agar adanya tindak lanjut yang lebih tegas dari pelanggaran yang dapat merugikan konsumen. Bagi Masyarakat, pelaku Pialang Berjangka dalam melaksanakan transaksi harus berdasarkan peraruran perundang-undangan dan ketentuan yang telah dibuat dalam perjanjian kontrak untuk perlindungan konsumen dan mengurangi perselisihan antara Pialang Berjangka dan konsumen yang dapat mengakibatkan kerugian. Kepada BAPPEBTI harus lebih ketat dalam pengawasan aktivitas dan transaksi yang dilakukan oleh Pialang Berjangka dan adanya langkah represif dan preventif dalam upaya mengurangi perselisihan antara Pialang Berjangka dan Konsumen. BAPPEBTl sebagai lembaga pengawas yang membawahi seluruh kegiatan perdagangan berjangka di seluruh Indonesia setidaknya harus memiliki ekstensi di setiap provinsi di Indonesia. Hal ini untuk memaksirnalkan tanggung jawab dalam pengawasan harian kegiatan perdagangan berjangka, khususnya pengawasan pialang berjangka. 


\section{DAFTAR PUSTAKA}

Fuadi, M. (2001). Pasar Modal Modern (Tinjauan Hukum). Citra Aditya Bakti, Bandung.

Hadikusuma, R. T. S. R., \& Sumantoro. (1996). Pengertian Pokok Hukum Perusahaan: Bentukbentuk Perusahaan yang Berlaku di Indonesia. Raja Grafindo Persada, Jakarta.

Kosasih, J. I., \& Haykal, H. (2020). BANK dan LEASING Lembaga Keuangan Strategis dalam Praktis Bisnis di Indonesia. CV. Mandar Maju, Bandung.

Purnomo, R. S. D., Serfiyani, C. Y., \& Hariyani, I. (2013). Pasar Komoditi. Jogya Bangkit, Yogyakarta.

Renti, A. M. (2012). Perdagangan Berjangka Komoditi dan Kajian Hukum Kontrak Derivatif Forex dan Indeks Saham Asing dalam Industri Perdagangan Berjangka di Indonesia. Jurnal Hukum \& Pembangunan, 42(1), 122-139.

Satrio, J. (1993). Hukum Perikatan, Perikatan yang Lahir dari Perjanjian: Buku II. Citra Aditya Bakti, Bandung.

Satrio, J. (2002). Hukum Jaminan Hak Jaminan Kebendaan. Citra Aditya Bakti, Bandung.

Serfianto, R., Purnomo, D., Serfiyani, C. Y., \& Hariyani, I. (2013). Pasar Uang \& Pasar Valas : Buku Pintar. Gramedia Pustaka Utama, Jakarta.

Singh, M. (2014). Current Trading Strategis. Gramedia Pustaka Indonesia, Jakarta.

Wardhani, I. K. (2016). Perlindungan Hukum Bagi Nasabah dalam Forex Trading Menurut UndangUndang No. 10 Tahun 2011 Tentang Perubahan Undang-Undang No.32 Taiiun 1999 Tentang Perdagangan Berjangka Komoditi (Studi Kasus di Pt. Finex Berjangka). Jurnal Lex Librum, $3(1), 445-464$. 